Pathology \& Oncology Research 2019;25(3):1153-1161. (doi: 10.1007/s12253-018-0557-7)

\title{
OA Green Postprint Manuscript
}

Link to Publisher version: https://link.springer.com/article/10.1007\% 2Fs12253-0180557-7

Patterns of regression in breast cancer after primary systemic treatment

Authors:

Tamás Zombori, M.D. ${ }^{1}$, Gábor Cserni, M.D., Ph.D., D.Sc. ${ }^{1,2}$

${ }^{1}$ Department of Pathology, University of Szeged, Faculty of Medicine

${ }^{2}$ Department of Pathology, Bács-Kiskun County Teaching Hospital

\section{Corresponding author:}

Tamás Zombori, M.D.

Department of Pathology, University of Szeged, Faculty of Medicine

Állomás u. 1. Szeged, 6725 Hungary

Phone: +36308447190

E-mail:zomtam@gmail.com

\section{Acknowledgment}

We gratefully acknowledge the assistance of Réka Némedi (MD) in collecting treatment related data of the patients and that of Mihály Dezső in photography work. This study was partly funded 
by the National Research, Development and Innovation Office grant GINOP-2.3.2-15-201600020

Conflicts of interest statement 
No editorial or financial conflicts of interest exist for this submission.

Abstract

Despite national guidelines, the evaluation of effects of primary systemic treatment (PST) in breast cancer is a complex challenge. Our aims were to evaluate the response patterns focusing on correlations of radiological and pathological tumor size, regression heterogeneity in different molecular subtypes, cellularity changes and the incidence of enlarged, multinucleated neoplastic cells related to therapy.

Slides of pretreatment biopsies and resection specimens of consecutive cases were reevaluated focusing on heterogeneity of regression per whole slide, and 40x or 100x magnification fields. Alteration in cellularity and the presence of multinucleated tumor giant cells were noted. The correlation of pathological and radiological sizes and their alterations were analyzed by Spearman rank correlation.

The present study included 106 tumors. A decrease in size (84.9\%) and cellularity (76.4\%) was noted in all molecular subtypes. Inhomogeneous regression was found in $45.3 \%$, with minor inhomogeneity in the majority. Scatter pattern regression was seen only in 8 cases (7.5\%). Significant correlations were found between the pathological and radiological sizes $(\mathrm{p}=0.02)$, and between the alterations of cellularity and pathological and radiological size ( $p=0.04 ; p=0.03$, respectively). Multinucleated tumor giant cells were noted in 17.9\% ( $\mathrm{n}=19)$, nearly exclusively in cases treated with PST including taxanes.

Regression inhomogeneity following PST is present in about half of the cases, and is not related to molecular subtypes. The evaluation of the maximum area of the tumor bed is recommended for the proper evaluation of regression. Multinucleated tumor giant cells are related to PST including taxane derivate, and may cause upgrading.

Key words: primary systemic therapy, breast cancer, regression pattern, molecular subtypes 
A 40-year-old woman with a cT2(34 mm)NOM0 grade 3 estrogen receptor (ER) positive and human epidermal growth factor receptor 2 (HER2) negative breast cancer of no special type (Fig. 1A) received 6 cycles of docetaxel, epirubicin and cyclophosphamide as primary systemic treatment (PST), showed substantial regression on imaging, and underwent breast conserving surgery with sentinel node biopsy. The localization metal clip was not included in the first excision and a re-excision was needed to remove the clip, too. The first surgical specimen included an empty tumor bed area with $11.4 \mathrm{~mm}$ greatest dimension, but the empty tumor bed was in the margin (Fig. 1B). The second specimen sent for histology also included the localization clip and a tumor bed area harboring both ductal carcinoma in situ and a 6 mm-large residual grade 3 invasive carcinoma (ypT1b) (Fig. 1C and 1D). The cited introductory example highlights that tumor regression may be misleadingly inhomogeneous, and this may lead to the false impression of complete regression on one end and lack of regression on the other end of the spectrum unless the full tumor bed is investigated.

PST of breast cancer has become more frequent recently. This approach to systemic treatment is currently applied in bulky $(>2 \mathrm{~cm})$ tumors or locally advanced cancers [1]. The radiologic and pathologic interpretation of regression is sometimes controversial due to some mismatch between the entities used for assessment. There is no internationally agreed consensus on how different imaging modalities should be priorized and specimen handling is also rather heterogeneous.

The presence or absence of regression is evaluated by radiologic modalities, namely ultrasonography (US), mammography and magnetic resonance imaging (MRI). This examination influences the continuation, shift or termination of PST and the multidisciplinary decision about surgical treatment. After the operation, the pathological examination reveals the degree of regression: pathological complete regression (pCR) on one end, and the complete lack of regression on the other end of the spectrum. The scale of regression affects further treatment decisions. Therefore, a standard approach to the evaluation of the breast specimen is crucial. To reach this aim, national guidelines have been developed in individual countries like Australia [2], Belgium [3], Germany [4], the United Kingdom [5], the Netherlands [6], the United States [7] and Hungary [8]. 
Despite these guidelines or reviews [9; 10] aiming at some uniformity in breast cancer reporting, there are several inconsistencies, namely in specimen work-up, definition of $\mathrm{pCR}$, patterns and grades of regression.

After PST, the identification of the tumor bed may be difficult because the tumor may have become less firm, and less well circumscribed. Therefore, gross examination must be correlated with the clinical and especially radiological localization to ensure that the correct area is sampled. Systematic sampling should include the grossly visible tumor bed or the location of clip markers and neighboring areas to incorporate the area involved by carcinoma before treatment [10]. Digital photos, specimen mammography images or drawings should be taken for helping the comparison between clinical and morphological findings.

Histopathological evaluation is based on sampling: representative areas are chosen for tissue blocks during grossing, and a tissue section represents about one thousandth of the whole thickness of the tissue block. It is obvious, that the more thorough the sampling, the more details one can discover under the microscope, especially in non-homogeneous lesions exemplified in the first paragraph and Figure 1.

In case of inhomogeneous, scattered focal regression, the assessment of tumor size may be problematic, as well. The dimension of the largest invasive focus may deviate from the largest dimension of the residual tumor affected area in the tumor bed (i.e. the extent) [11].

According to the United States' Food and Drug Administration (FDA), 'Pathological complete response is defined as the absence of residual invasive cancer (ypT0ypN0 or ypT0isypN0) on evaluation of the complete resected breast specimen and all sampled regional lymph nodes following completion of neoadjuvant systemic therapy' [12].The AJCC has endorsed the same definition [13]. This recommendation is based on the findings of the Collaborative Trials in Neoadjuvant Breast Cancer project. In this study, there was no difference in event-free and overall survival of patients having ypT0ypN0 or ypTisypN0 breast cancer [14]. On the contrary, the German and Austrian Breast Groups demonstrated significant worsening in event-free survival of ypTisypN0 versus ypT0ypN0 breast cancer cases [15]. Therefore, an alternative definition of complete response was proposed by this group, which excludes both residual ductal carcinoma in situ (DCIS) and invasive carcinoma in the breast (ypT0ypN0 only). 
Regression and its scale can be characterized by different parameters, like the size of residual invasive carcinoma, lymph node status, tumor cellularity, tumor grade, proportion of tumor remaining in breast $(\%)$ and finally the size of tumor bed in two dimensions. Several regression grading systems based on these parameters have been introduced and validated, including those described by Miller and Payne [16], Pinder [17], Denkert and Sinn [18] and Sataloff [19].

Another feature of response to neoadjuvant therapy is homogeneity or heterogeneity of the regression. According to Provenzano and coworkers, the patterns of residual disease are the following: homogenous regression (cellularity decreased, size unchanged), inhomogeneous regression (cellularity decreased, size variable, small areas without residual disease), "scatter pattern" (cellularity decreased, size variable, tumor bed slides without residual disease) and "concentric shrinkage" (CS) (size decreased, cellularity similar) [10]. Especially the "scatter pattern" may lead to diagnostic pitfalls if not systematically sampled.

Not only the size and cellularity change following PST, but grade may also be altered. After PST, bizarre and/or macronucleated neoplastic giant cells may sometimes be found in the tumor bed. These cells are generally attributed to the effects of chemotherapy. The presence of these bizarre cells may increase the posttreatment grade, whereas a reduction in the proliferating cells may decrease it.

The aims of the present study were to evaluate the response patterns in breast cancers after PST, focusing on correlations of radiological and pathological tumor sizes, regression heterogeneity in the tumor bed and in the axilla in different molecular subtypes of breast cancer, cellularity changes between biopsy and resection specimen, correlation between cellularity and size alterations and the incidence of macronucleated, bizarre neoplastic cells related to therapy.

\section{Materials and methods}

Consecutive invasive breast carcinomas treated with PST and operated on at the BácsKiskun County Teaching Hospital, Kecskemét or at the Department of Surgery, University of Szeged from 2015 through February 2018 and from 2013 through May 2018, respectively were included. Additionally some earlier cases (from between 2010-2014) collected for a 
previous study on PST $(n=8)$ were also included. Exclusion criteria were unavailability of slides of either the biopsy or the excision specimen and primary endocrine therapy.

Clinical data, namely age, gender, laterality, type of surgery, pre- and posttreatment size determined by US, mammography and MRI (as available), primary systemic therapy were collected from medical charts. Pathological data including ER, progesterone receptor (PR) and HER-2 status, ypT and ypN categories [13], TR and NR tumor and node regression categories [20], pre- and posttreatment histological grade, pathological size (both the largest invasive focus and extent of the area involved by tumor, either invasive or in situ) were obtained from the histopathology reports. The immunohistochemical surrogate classification of molecular subtypes of breast carcinomas was utilized according to the St. Gallen Consensus Conference [21]. The latest recommendations of American Society of Clinical Oncology were applied for the evaluation of HER-2 immunohistochemical staining [22].

Both departments have used the same work-up methodology recommended by the 3rd Hungarian Consensus Conference on Breast Cancer [8] including radiological localization, systematic sampling and clinical-pathological correlation on multidisciplinary meetings.

All hematoxyline-eosin stained tumor (bed) containing slides of biopsy and excision specimens were analyzed. The cellularity was estimated by two pathologists (TZ \& GC) both on biopsy and excision specimens. Consensus was always reached.

The tumor bed areas showing complete regression or the absence of any regression pattern were evaluated on low (4x) and medium (10x) power fields (field areas: $0.24 \mathrm{~mm}^{2}$ and $0.005 \mathrm{~mm}^{2}$, respectively). The presence of whole slides, any low power field or any medium power field showing complete response or the lack of any response were noted. Homogenous regression was defined as pCR (Fig.2A), absence of regression on all slides (Fig.2B) and uniform degree of regression on all slides (Fig.2C). Any other pattern was perceived as inhomogeneous response (Fig.2E-G). The latter included the so called "scatter pattern" [17], the CS [17], which was identified in case of reduction of tumor size with similar cellularity (Fig.2D).

The cells having enlarged cytoplasm, multiple and/or enlarged bizarre hyperchromatic nuclei with different size and shape were labelled as "monster cells" for the purpose of this study (Fig.2H-I). 
The slides of axillary sentinel lymph node excisions and/or axillary lymph node dissections were reevaluated and the presence or absence of metastasis and regression were documented. If metastatic nodes were seen with and without regression, inhomogeneous axillary response was identified.

The alteration of pre- and posttreatment cellularity and size; and the correlation between radiological (exclusively uniformly available US data) and pathological size were analyzed by the Spearman rank model. All statistical tests were one-sided, and $p<0.05$ values were considered statistically significant. We utilized the SPSS Statistics software (IBM, SSPS 22.0, Armonk, NY USA).

\section{Results}

In this series, 106 cases were included: 56 and 50 patients from the University of Szeged and the Bács-Kiskun County Teaching Hospital, respectively. The basic clinical characteristics of these cases, namely age, type of surgery, histological type of tumor, ypT, ypN categories, pretreatment grade and therapy received are summarized in Table 1.Seven patients having stage IV disease defined by distant metastasis received palliative chemotherapy before surgery.

The morphological parameters evaluated are displayed in Table 2. In all IHC approached molecular subtypes defined by the St. Gallen Consensus Conference in 2013, diminution was the most frequent size alteration after PST. The Spearman rank correlation revealed that the concordance between post-treatment pathological size and radiological size (defined by US examination) was high $(\mathrm{p}=0.002)$.

Regarding the homogeneity of regression, the luminal A, HER-2 and triple negative breast cancers (TNBCs) showed more homogeneity, whereas luminal B cases demonstrated more inhomogeneity. Unfortunately, statistical analysis could not been applied due to the low case number in the groups. Lack of any regression, uniform degree of regression and pCR were observed in $7.5 \%, 18.8 \%$ and $28.3 \%$ of all cases, respectively. The vast majority of inhomogeneous regression was minor inhomogeneity (36.7\% of all cases). The scatter pattern was identified in only 8 cases $(7.5 \%)$, while $\mathrm{CS}$ was the rarest $(\mathrm{n}=2 ; 1.8 \%)$. The regression inhomogeneity is demonstrated in Table 3 displaying the distribution of complete regression and the lack of any regression patterns at the different magnifications evaluated. In the lymph 
node specimens, homogeneity was more frequent (homogeneity: $45.3 \%$ versus inhomogeneity: $23.5 \%$ of all cases). In cases having neither metastasis nor regression in the lymph nodes, homogeneity of regression or its lack could not be evaluated (31.2\%).

Cellularity changes reflected decrease in most cases (two thirds of all patients) but an increase was recorded in a significant minority (15.1\%). The correlation between changes in cellularity and the alterations of post-treatment pathological and radiological tumor sizes compared to the pretreatment US size were significant $(\mathrm{p}=0.04$ and $\mathrm{p}=0.03$, respectively). After exclusion of cases showing pCR following PST (where grade alteration was not interpretable) the grade of tumors was unchanged in $72.4 \%$. Upgrading and downgrading were detected in 10 and 10 cases (13.8\% and 13.8\%), respectively. The latter was not seen among patients having TNBC.

"Monster" cells were seen in 17.9\% $(\mathrm{n}=19)$ of all cases. They were present in pre- and posttreatment grade 2 and 3 tumors exclusively. Their possible influence on grade alteration and association with PST are demonstrated in Table 4. Among these findings, the following are underlined: in 5 cases, upgrading (grade 2 to post-treatment y-grade 3 ) was detected in presence of "monster" cells and the monster cells were present only (all but one case) in patients who received PST including a taxane.

No correlation was found between the molecular subtypes and treatment related alteration in (pathological) size, cellularity, grade, the homogeneity of regression in lymph node specimens and presence of "monster" cells.

\section{Discussion}

The concepts of PST were developed in the last years and offer an alternative option for patients having primary breast cancer. The aims of PST are combination of systemic treatment and surgical treatment in order to eliminate all tumor cells, down staging breast cancers to make them operable by breast conserving options, and enabling the assessment of regression by pathological means [23-25]. In PST studies, the pathological diagnosis is the most important parameter for the generation of study endpoints [26]. The histopathological changes after PST are complex, therefore careful systematic analysis of the specimen is required for accurate diagnosis and treatment. The standardization of specimen handling and 
histological interpretation is essential for approaching pCR as an indicator in PST studies, or for measuring residual disease [10].

Although one of the most cardinal features of residual disease is the tumor size, it is often difficult to determine after PST. Besides the hardships of systematic sampling of the tumor bed, residual tumor may be present as multiple, small scattered foci. In the latter case, the size of the largest invasive focus determines the ypT category according to the $8^{\text {th }}$ edition of the AJCC staging system [13], while the extent defined by the largest dimension inclusive of all independent invasive foci may be better for comparison with radiologic size [12]. Our findings have demonstrated, that pathological tumor size correlates with radiological (US) size, and the alteration of pathological size is in keeping with radiological findings [27; 28].

Primary chemotherapy selectively eliminates the proliferating cells, therefore the mitotic activity and the cellularity may decrease. Though, the change in cellularity is one of the most representative features of PST [29], it is not recorded routinely in the histopathological reports, because it is not easy to assess, lacks standardization and is an important parameter in only some tumor-response systems [16;30] while it is not one in others [31-33]. Cellularity is utilized in two regression grading systems: in the Miller-Payne and in the Residual Cancer Burden system (RCB). Regarding the five-tiered Miller-Payne system, the pre- and post PST cellularity are compared, and the presence of invasive carcinoma is considered [16]. The four-tiered RCB is based on the size of the tumor bed in two dimensions, tumor cellularity in the post-treatment specimen, the proportion of DCIS in residual cancer, the number of lymph nodes with residual metastasis and the size of the largest lymph node metastasis [30]. In the present series, biopsies taken before PST and resection specimen were evaluated for cellularity changes. In the vast majority of the cases, cellularity has declined and a significant correlation was detected between alterations of cellularity and (pathological) size.

Our findings suggest that homogeneity and inhomogeneity of regression are not associated with any molecular subtypes, and both are present approximately in half of the cases. The majority of inhomogeneous regression represented minor inhomogeneity seen in differences between one and the other medium or low power field, while the scatter pattern and CS were exceptionally rare. Although, the most remarkable pattern is the scatter pattern regarding the problems of tumor bed sampling (Figure 1 and introductory example), where 
complete slides may be present without residual cancer, minor heterogeneity may also cause diagnostic controversy if only core biopsy is taken after PST.

Several ongoing or completed studies on PST feature post-PST biopsies as parts of the design [34-38]. By taking interim or final biopsies, pathological response and the effects of treatment can be characterized. Tumor heterogeneity, especially the scatter pattern of regression may have an impact on these studies. Limited sampling by biopsies may be the source of misinterpretations, if the biopsy is taken from the part of tumor bed showing complete response, or another part lacking any response. To avoid these diagnostic pitfalls, generous sampling by multiple biopsies is recommended for cases showing the extremes on the scale of regression, if the assessment of the complete tumor bed is not feasible. The results may also have an impact on the management of cases similar to the introductory example: an empty tumor bed with tumor bed on the inked margin may not be a perfect evidence of pCR or complete tumor resection.

Histological grade of breast cancer is one of the most established traditional prognostic factors. Honkoop and coworkers have found significant decline in mitotic activity following PST [39], while Sharkey et al have identified significant increase of nuclear pleomorphism [40]. While the decline of mitotic count can lead to "downgrading", more severe nuclear atypia could result in "upgrading". The result of these contradirectional changes may alter the posttreatment histological grade. We have demonstrated that up- and downgrading are rare, especially because the majority of PST case belong to grade 3. In half of the cases with upgrading, monster cells were present.

The monster cells (Figure 2H-I) are giant tumor cells often having hyperchromatic macronuclei or multilobated or multiple nuclei and they are associated with effects of PST [40]. The presence of these cells was associated with taxane treatment. The principal effect of taxanes is the disruption of microtubule function, including the blockage of the mitotic spindle. Microtubules are essential to cell division, and taxanes stabilize GDP-bound tubulin in the microtubule, thereby inhibiting the process of cell division as depolymerization is prevented. The tumor cells are not able to divide after the duplication of their chromatin content, and the result may be the formation of macronucleated "monster" cells. Our findings suggest that the presence of these monster cells may increase nuclear atypia and therefore it may lead to upgrading following PST. Due to polyploidization, such cells are also expected to 
show an increased copy number of many genes, including HER2, leading to a post-treatment positive status of questionable therapeutic significance in these cells [41].

Limitations of the present study could be the low number of cases and the exclusion of patients receiving primary hormone therapy (PHT). Fukada and coworkers have reported that CS is significantly more frequent in luminal breast cancers following PHT, and these patients had significantly better outcome than patients having other patterns [42]. In contrast, there was no significant correlation between regression patterns and molecular subtypes in present work. This discrepancy may be explained by the exclusion of cases with PHT.

To our knowledge, this is the first study describing the distribution of regression heterogeneity according to molecular subtypes. Our findings suggest that regression may be inhomogeneous in half of the cases, and it does not seem to be related to any molecular subtype, therefore the evaluation of the whole tumor bed is recommended for the best assessment of regression. The "monster" cells are related to PST including taxane derivate, and may cause upgrading in tumors with non-high grade nuclei at the start of PST. 


\section{References}

1. Thompson AM, Moulder-Thompson SL (2012) Neoadjuvant treatment of breast cancer. Ann Oncol 10:x231-6. https://doi.org/10.1093/annonc/mds324

2. Royal College of Pathologists of Australasia (2012) Invasive Breast cancer structured reporting protocol (2nd Edition) https://www.rcpa.edu.au/getattachment/7b70b3e5-5dca-403f893e-638815f487b1/Protocol-invasive-breast-cancer.aspx. Accessed 26 June 2018

3. K. Lambein, K. Van de Vijver, D. Faverly, C. Colpaert (2011) Belgian guidelines for laboratory handling and pathology reporting of breast carcinoma after neoadjuvant therapy. Belg J Clin Oncol 5:144-153.

4. Arbeitsgemeinschaft Gynäkologische Onkologie Studiengruppe (AGO) https://www.agoonline.de/fileadmin/downloads/leitlinien/mamma/201803/EN/Gesamt_PDF_Englisch/Updated_Guidelines_2018.pdf. Accessed 26 June 2018

5. NHS Breast Screening Program (2005) Pathology reporting of breast disease: A joint document incorporating the third edition of the NHS Breast Screening Programs Guidelines for pathology reporting in breast cancer screening and the second edition of the Royal College of Pathologists' Minimum dataset for breast cancer histopathology. NHSBSP Publication No 58. NHS Cancer Screening Programs jointly with the Royal College of Pathologists.

6. Integraal Kankercentrum Nederland (2012) Beoordeling na neoadjuvante chemo- of endocriene therapie. http://www.oncoline.nl/breastcancer 2012. Accessed 26 June 2018

7. College of American Pathologists. Protocol for the examination of specimens from patients with invasive carcinoma of the breast. http://www.cap.org/ShowProperty?nodePath=/UCMCon/Contribution\%20Folders/WebConten t/pdf/cp-breast-invasive-16protocol-3300.pdf Accessed 36 June 2018

8. Cserni G, Kulka J, Francz M, Járay B, Kálmán E, Kovács I, Krenács T, Udvarhelyi N, Vass L (2016) Pathological diagnosis, work-up and reporting of breast cancer. Recommendations of the 3rd Hungarian Consensus Conference on Breast Cancer. Magy Onkol 60:209-28. [Hungarian] 
9. Park CK, Jung WH, Koo JS (2016) Pathologic evaluation of breast cancer after neoadjuvant therapy. J Pathol Transl Med 50:173-80. https://doi.org/10.4132/jptm.2016.02.02.

10. Provenzano E, Bossuyt V, Viale G, Cameron D, Badve S, Denkert C, MacGrogan G, PenaultLlorca F, Boughey J, Curigliano G, Dixon JM, Esserman L, Fastner G, Kuehn T, Peintinger F, von Minckwitz G, White J, Yang W, Symmans WF (2015) Residual Disease Characterization Working Group of the Breast International Group-North American Breast Cancer Group Collaboration. Standardization of pathologic evaluation and reporting of postneoadjuvant specimens in clinical trials of breast cancer: recommendations from an international working group. Mod Pathol 28:1185-201. https://doi.org/10.1038/modpathol.2015.74.

11. Tot $\mathrm{T}$ (2012) The role of large-format histopathology in assessing subgross morphological prognostic parameters: a single institution report of 1000 consecutive breast cancer cases. Int J Breast Cancer. 2012:395415. https://doi.org/10.1155/2012/395415.

12. U.S. Food and Drug Administration (2014) Guidance for Industry: Pathological complete response in neoadjuvant treatment of high-risk early-stage breast cancer: use as an endpoint to support accelerated approval.

http://www.fda.gov/downloads/Drugs/GuidanceComplianceRegulatoryInformation/Guidances /UCM305501.pdf Accessed 26 June 2018

13. AJCC (2016) Cancer staging manual 8th edn. Springer, Chicago

14. Cortazar P, Zhang L, Untch M, Mehta K, Costantino JP, Wolmark N, Bonnefoi H, Cameron D, Gianni L, Valagussa P, Swain SM, Prowell T, Loibl S, Wickerham DL, Bogaerts J, Baselga J, Perou C, Blumenthal G, Blohmer J, Mamounas EP, Bergh J, Semiglazov V, Justice R, Eidtmann H, Paik S, Piccart M, Sridhara R, Fasching PA, Slaets L, Tang S, Gerber B, Geyer CE Jr, Pazdur R, Ditsch N, Rastogi P, Eiermann W, von Minckwitz G (2014) Pathological complete response and long-term clinical benefit in breast cancer: the CTNeoBC pooled analysis. Lancet 384:164-72. https://doi.org/10.1016/S0140-6736(13)62422-8.

15. von Minckwitz G, Untch M, Blohmer JU, Costa SD, Eidtmann H, Fasching PA, Gerber B, Eiermann W, Hilfrich J, Huober J, Jackisch C, Kaufmann M, Konecny GE, Denkert C, Nekljudova V, Mehta K, Loibl S (2012) Definition and impact of pathologic complete response on prognosis after neoadjuvant chemotherapy in various 
intrinsic breast cancer subtypes. J Clin Oncol 30:1796-804.

https://doi.org/10.1200/JCO.2011.38.8595.

16. Mamounas EP, Anderson SJ, Dignam JJ, Bear HD, Julian TB, Geyer CE Jr, Taghian A, Wickerham DL, Wolmark N (2012) Predictors of locoregional recurrence after neoadjuvant chemotherapy: results from combined analysis of National Surgical Adjuvant Breast and Bowel Project B-18 and B-27. J Clin Oncol 30:3960-6. https://doi.org/10.1200/JCO.2011.40.8369.

17. Pinder SE, Provenzano E, Earl H, Ellis IO (2007) Laboratory handling and histology reporting of breast specimens from patients who have received neoadjuvant chemotherapy. Histopathology 50:409-17. https://doi.org/10.1111/j.13652559.2006.02419.x

18. Denkert C, Schickling O, von Minckwitz G (2006) Preoperative chemotherapy in breast cancer and the development of new predictive markers. Verh Dtsch Ges Pathol 90:114-23. [German]

19. Sataloff DM, Mason BA, Prestipino AJ, Seinige UL, Lieber CP, Baloch Z (1995) Pathologic response to induction chemotherapy in locally advanced carcinoma of the breast: a determinant of outcome. J Am Coll Surg 180:297-306.

20. Wells CA, Amendoeira I, Bellocq JP, Bianchi S, Boecker W, Borisch B, Bruun Rasmussen B, Callagy GM, Chmielik E, Cordoba A, Cserni G, Decker T, DeGaetano J, Drijkoningen M, Ellis IO, Faverly DR, Foschini MP, Frković-Grazio S, Grabau D, Heikkilä P, Iacovou E, Jacquemier J, Kaya H, Kulka J, Lacerda M, Liepniece-Karele I, Martinez-Penuela J, Quinn CM, Rank F, Regitnig P, Reiner-Concin A, Sapino A, Tot T, Van Diest PJ, Varga Z, Wesseling J, Zolota V, Zozaya-Alvarez E. (2012) Pathology update. Quality assurance guidelines for pathology. In: European guidelines for quality assurance in breast cancer screening and diagnosis. Fourth edition, Supplements. Perry N, Broeders M, de Wolf C, Törnberg S, Holland R, von Karsa L (eds.). European Commission, Office for Official Publications of the European Union, Luxembourg, pp. 73-120.

21. Goldhirsch A, Winer EP, Coates AS, Gelber RD, Piccart-Gebhart M, Thürlimann B, Senn HJ; Panel members (2013) Personalizing the treatment of women with early 
breast cancer: highlights of the St Gallen International expert consensus on the primary therapy of early breast cancer 2013. Ann Oncol 24:2206-23.

https://doi.org/10.1093/annonc/mdt303.

22. Giordano SH, Temin S, Chandarlapaty S, Crews JR, Esteva FJ, Kirshner JJ, Krop IE, Levinson J, Lin NU, Modi S, Patt DA, Perlmutter J, Ramakrishna N, Winer EP, Davidson NE (2018) Systemic therapy for patients with advanced human epidermal growth factor receptor 2-positive breast cancer: ASCO Clinical practice guideline update. J Clin Oncol [Epub ahead of print] https://doi.org/10.1200/JCO.2018.79.2697.

23. Kaufmann M, von Minckwitz G, Smith R, Valero V, Gianni L, Eiermann W, Howell A, Costa SD, Beuzeboc P, Untch M, Blohmer JU, Sinn HP, Sittek R, Souchon R, Tulusan AH, Volm T, Senn HJ (2003) International expert panel on the use of primary (preoperative) systemic treatment of operable breast cancer: review and recommendations. J Clin Oncol 21:2600-8. https://doi.org/10.1200/JCO.2003.01.136

24. Kaufmann M, Hortobagyi GN, Goldhirsch A, Scholl S, Makris A, Valagussa P, Blohmer JU, Eiermann W, Jackesz R, Jonat W, Lebeau A, Loibl S, Miller W, Seeber S, Semiglazov V, Smith R, Souchon R, Stearns V, Untch M, von Minckwitz G (2006) Recommendations from an international expert panel on the use of neoadjuvant (primary) systemic treatment of operable breast cancer: an update. J Clin Oncol 24:1940-9. https://doi.org/10.1200/JCO.2005.02.6187

25. von Minckwitz G, Blohmer JU, Raab G, Löhr A, Gerber B, Heinrich G, Eidtmann H, Kaufmann M, Hilfrich J, Jackisch C, Zuna I, Costa SD; German Breast Group (2005) In vivo chemosensitivity-adapted preoperative chemotherapy in patients with earlystage breast cancer: the GEPARTRIO pilot study. Ann Oncol 16:56-63. https://doi.org/10.1093/annonc/mdi001

26. Chollet P, Amat S, Cure H, de Latour M, Le Bouedec G, Mouret-Reynier MA, Ferriere JP, Achard JL, Dauplat J, Penault-Llorca F (2002) Prognostic significance of a complete pathological response after induction chemotherapy in operable breast cancer. Br J Cancer 86:1041-6. https://doi.org/10.1038/sj.bjc.6600210

27. Marinovich ML, Macaskill P, Irwig L, Sardanelli F, Mamounas E, von Minckwitz G, Guarneri V, Partridge SC, Wright FC, Choi JH, Bhattacharyya M, Martincich L, Yeh 
E, Londero V, Houssami N (2015) Agreement between MRI and pathologic breast tumor size after neoadjuvant chemotherapy, and comparison with alternative tests: individual patient data meta-analysis. BMC Cancer 15:662. https://doi.org/10.1186/s12885-015-1664-4.

28. Lee SC, Grant E, Sheth P, Garcia AA, Desai B, Ji L, Groshen S, Hwang D, Yamashita M, Hovanessian-Larsen L (2017) Accuracy of Contrast-Enhanced Ultrasound Compared With Magnetic Resonance Imaging in Assessing the Tumor Response After Neoadjuvant Chemotherapy for Breast Cancer. J Ultrasound Med 36:901-911. https://doi.org/10.7863/ultra.16.05060.

29. Rajan R, Poniecka A, Smith TL, Yang Y, Frye D, Pusztai L, Fiterman DJ, Gal-Gombos E, Whitman G, Rouzier R, Green M, Kuerer H, Buzdar AU, Hortobagyi GN, Symmans WF (2004) Change in tumor cellularity of breast carcinoma after neoadjuvant chemotherapy as a variable in the pathologic assessment of response. Cancer 100:1365-73. https://doi.org/10.1002/cncr.20134

30. Abrial SC, Penault-Llorca F, Delva R, Bougnoux P, Leduc B, Mouret-Reynier MA, Mery-Mignard D, Bleuse JP, Dauplat J, Curé H, Chollet P (2005) High prognostic significance of residual disease after neoadjuvant chemotherapy: a retrospective study in 710 patients with operable breast cancer. Breast Cancer Res Treat 94:255-63. https://doi.org/10.1007/s10549-005-9008-8

31. Diaz J, Stead L, Shapiro N, Newell R, Loudig O, Lo Y, Sparano J, Fineberg S (2013) Mitotic counts in breast cancer after neoadjuvant systemic chemotherapy and development of metastatic disease. Breast Cancer Res Treat 138:91-7. https://doi.org/10.1007/s10549-013-2411-7

32: Boughey JC, Peintinger F, Meric-Bernstam F, Perry AC, Hunt KK, Babiera GV, Singletary SE, Bedrosian I, Lucci A, Buzdar AU, Pusztai L, Kuerer HM (2006) Impact of preoperative versus postoperative chemotherapy on the extent and number of surgical procedures in patients treated in randomized clinical trials for breast cancer. Ann Surg 244:464-70. https://doi.org/10.1097/01.sla.0000234897.38950.5c

33. Carey LA, Metzger R, Dees EC, Collichio F, Sartor CI, Ollila DW, Klauber-DeMore N, Halle J, Sawyer L, Moore DT, Graham ML (2005) American Joint Committee on 
Cancer tumor-node-metastasis stage after neoadjuvant chemotherapy and breast cancer outcome. J Natl Cancer Inst 97:1137-42. https://doi.org/10.1093/jnci/dji206

34. Neoadjuvant response-guided treatment of HER2 positive breast cancer (PREDIX HER2). ClinicalTrials.gov Identifier: NCT02568839

https://clinicaltrials.gov/ct2/show/NCT02568839?cond=breast+neoadjuvant + treatment \&rank=31 Accessed 2 August 2018

35. Efficacy and safety of Cabazitaxel versus weekly Paclitaxel as neo-adjuvant treatment in patients with triple negative or luminal B/HER2 normal BC (GENEVIEVE).

ClinicalTrials.gov Identifier: NCT01779479

https:/clinicaltrials.gov/ct2/show/NCT01779479?cond=breast+neoadjuvant + treatment $\underline{\text { \&rank}=69}$ Accessed 2 August 2018

36. Neoadjuvant Letrozole plus Metformin vs Letrozole plus Placebo for ER-positive postmenopausal breast cancer. ClinicalTrials.gov Identifier: NCT01589367 https://clinicaltrials.gov/ct2/show/NCT01589367?cond=breast+neoadjuvant+treatment \&rank=97 Accessed 2 August 2018

37. Neoadjuvant Tamoxifen in locally advanced breast cancer in a low/middle income country. ClinicalTrials.gov Identifier: NCT02806544 https://clinicaltrials.gov/ct2/show/NCT02806544?cond=breast+neoadjuvant+treatment $\underline{\text { draw }=2 \& \text { rank }=101}$ Accessed 2 August 2018

38. Leary A, Evans A, Johnston SR, A'Hern R, Bliss JM, Sahoo R, Detre S, Haynes BP, Hills M, Harper-Wynne C, Bundred N, Coombes G, Smith I, Dowsett M (2015) Antiproliferative effect of Lapatinib in HER2-positive and HER2-negative/HER3-high breast cancer: Results of the presurgical randomized MAPLE trial (CRUKE/06/039). Clin Cancer Res 21:2932-40. https://doi.org/10.1158/1078-0432.CCR-14-1428.

39. Honkoop AH, Pinedo HM, De Jong JS, Verheul HM, Linn SC, Hoekman K, Wagstaff J, van Diest PJ (1997) Effects of chemotherapy on pathologic and biologic characteristics of locally advanced breast cancer. Am J Clin Pathol 107:211-8. 
40. Sharkey FE, Addington SL, Fowler LJ, Page CP, Cruz AB (1996) Effects of preoperative chemotherapy on the morphology of resectable breast carcinoma. Mod Pathol 9:893-900.

41. Valent A, Penault-Llorca F, Cayre A, Kroemer G (2013) Change in HER2 (ERBB2) gene status after taxane-based chemotherapy for breast cancer: polyploidization can lead to diagnostic pitfalls with potential impact for clinical management. Cancer Gen 206:37-41. https://doi.org/10.1016/j.cancergen.2012.12.001

42. Fukada I, Araki K, Kobayashi K, Shibayama T, Takahashi S, Gomi N, Kokubu Y, Oikado K, Horii R, Akiyama F, Iwase T, Ohno S, Hatake K, Sata N, Ito Y (2018) Pattern of tumor shrinkage during neoadjuvant chemotherapy is associated with prognosis in low-grade luminal early breast cancer. Radiology 286:49-57. https://doi.org/10.1148/radiol.2017161548. 


\section{Figure legends:}

Figure 1. Example case with inhomogeneous (scatter pattern) regression.

A. Cellular tumor on core needle biopsy (HE, 40x)

B. Empty tumor bed with remnants of an intraductal papilloma in the firstly excised surgical specimen. No margin labeling ink on tumor (free margin?), but ink on the empty tumor bed. (HE, 40x)

C. Second surgical specimen included both areas of empty tumor bed (top right third) and residual invasive carcinoma $(\mathrm{HE}, 40 \mathrm{x})$

D. Higher magnification of part $\mathrm{C}$, with residual invasive tumor cell clusters (HE, 400x)

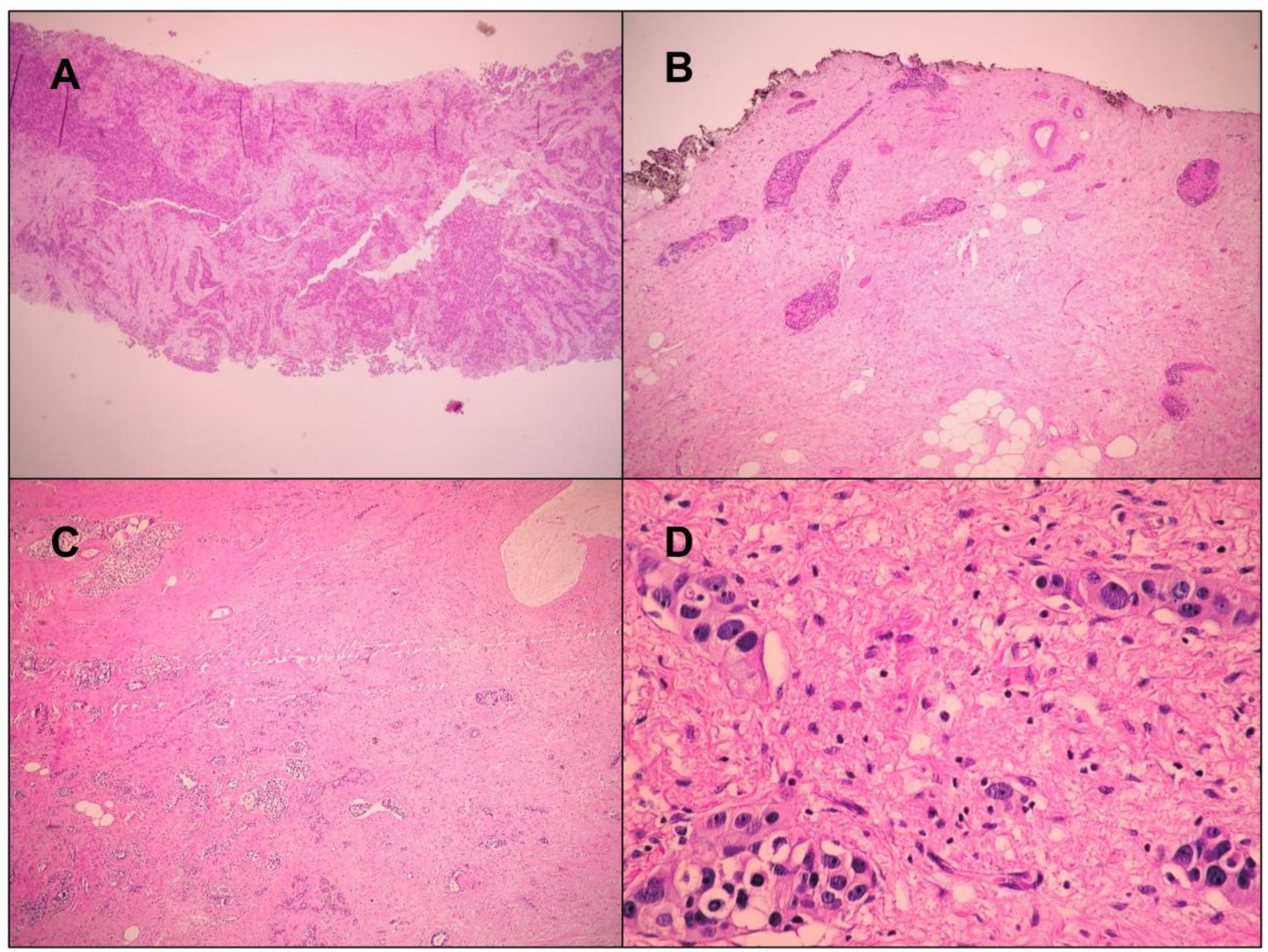


Figure 2. Patterns of regression and peculiar cellular changes (monster cells) in post-treatment specimens.
A. Complete pathological regression (HE,40x)
B. Absence of any regression in the tumor bed (HE, 40x)
C. Homogenous regression $(\mathrm{HE}, 40 \mathrm{x})$
D. Concentric shrinkage pattern (HE, 40x)
E. Inhomogenous regression in a tumor bed. Big red circle and small yellow circle display 40x and 100x field area, respectively. (HE, 1x)
F. 40x field area of tumor bed on "E" slide shows complete response (HE, 40x)
G. 10x field area of tumor bed on "E" slide lacks any regression (HE, 100x)
H.-and I. bizarre macronucleated "monster" cells (HE, 400x) 


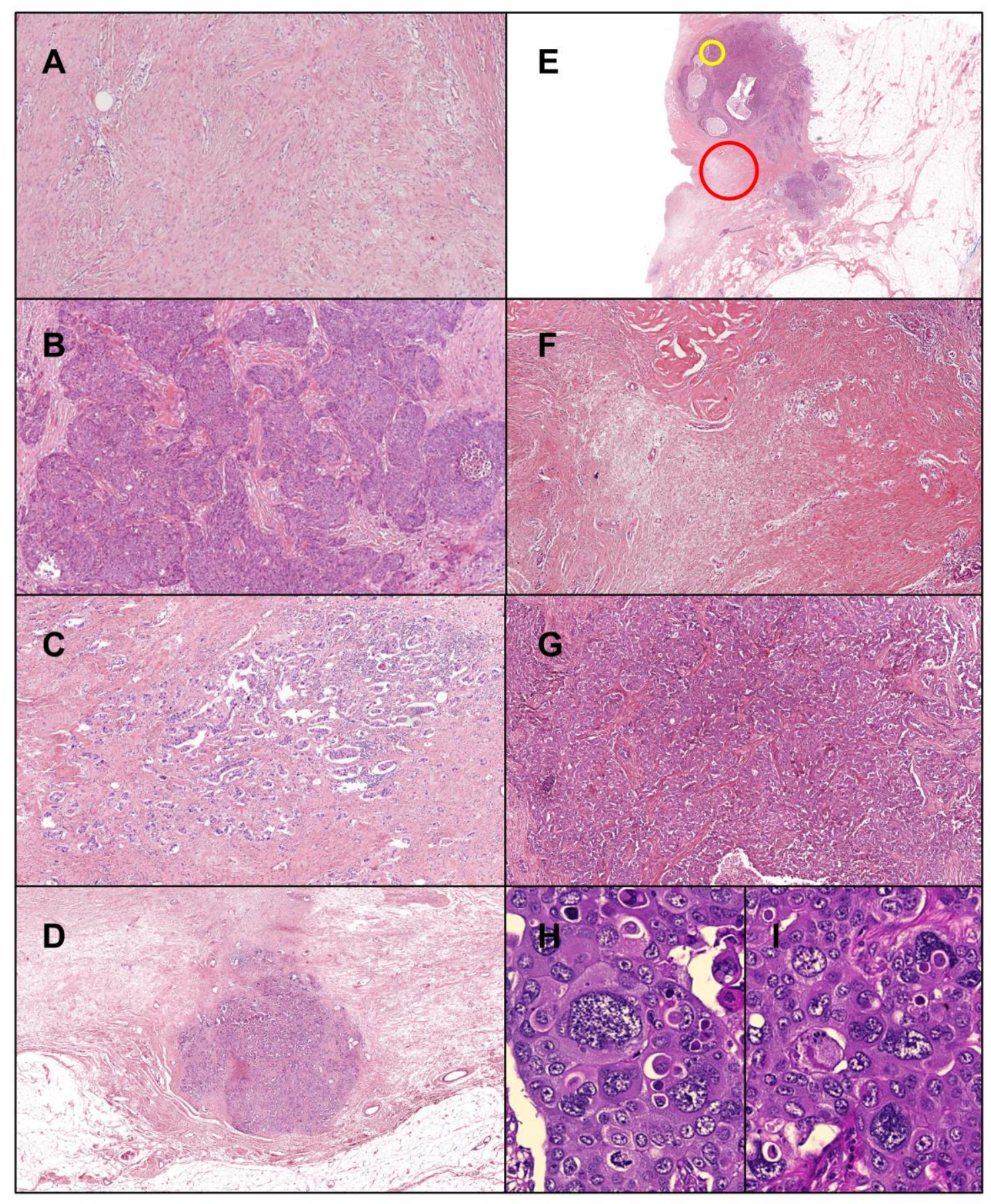


Table 1. Clinical characteristics of patients. (SLND: sentinel lymph node dissection, ALND: axillary lymph node dissection, NST: breast carcinoma of no special type, ypT and ypN: categories defined by the $8^{\text {th }}$ edition of Cancer staging manual introduced by AJCC [13:AJCC])

\begin{tabular}{|c|c|}
\hline \multicolumn{2}{|l|}{ Clinical parameters } \\
\hline \multicolumn{2}{|l|}{ Age (year) } \\
\hline Range & $32-77$ \\
\hline mean / median & $54.5 / 55$ \\
\hline \multicolumn{2}{|l|}{ Type of surgery $(\mathrm{n} ;(\%))$} \\
\hline Mastectomy & $71(66.9)$ \\
\hline breast conserving surgery & $35(33.1)$ \\
\hline \multicolumn{2}{|l|}{ Type of lymphadenectomy (n; (\%)) } \\
\hline SLND & $35(33.1)$ \\
\hline ALND & $80(75.4)$ \\
\hline SLND+ALND & $10(9.4)$ \\
\hline None & $1(0.9)$ \\
\hline \multicolumn{2}{|l|}{ Histological type of tumor $(\mathrm{n} ;(\%))$} \\
\hline NST & $100(94.5)$ \\
\hline Lobular & $4(3.7)$ \\
\hline Other & $2(1.8)$ \\
\hline \multicolumn{2}{|l|}{ ypT (n; (\%)) } \\
\hline урТ0 & $25(23.6)$ \\
\hline ypTis & $5(4.7)$ \\
\hline ypT1a & $8(7.5)$ \\
\hline урT1b & $9(8.6)$ \\
\hline урT1с & $18(16.9)$ \\
\hline ypT2 & $30(28.3)$ \\
\hline ypT3 & $9(8.6)$ \\
\hline ypT4 & $2(1.8)$ \\
\hline \multicolumn{2}{|l|}{ ypN (n; (\%)) } \\
\hline ypNo & $55(51.8)$ \\
\hline ypN1 & $26(24.5)$ \\
\hline ypN2 & $12(11.3)$ \\
\hline ypN3 & $11(10.3)$ \\
\hline no data & $2(1.8)$ \\
\hline \multicolumn{2}{|l|}{ Grade on core needle biopsy (n; (\%)) } \\
\hline 1 & $6(5.6)$ \\
\hline 2 & $41(38.7)$ \\
\hline 3 & $59(55.7)$ \\
\hline \multicolumn{2}{|l|}{ Treatment (n; (\%)) } \\
\hline anthracycline $+/$ - targeted therapy & $9(8.6)$ \\
\hline taxane +/- platinum derivatives & $27(25.4)$ \\
\hline anthracycline + taxane & $70(66.0)$ \\
\hline
\end{tabular}


Table 2. Morphological features of cases evaluated, displayed according to the molecular subtypes of breast cancer [20]

\begin{tabular}{|c|c|c|c|c|}
\hline & Luminal A & Luminal B & HER-2 & TNBC \\
\hline \multirow[t]{2}{*}{ Morphological variable } & $\mathrm{n}(\%)$ & $\mathrm{n}(\%)$ & $\mathrm{n}(\%)$ & $\mathrm{n}(\%)$ \\
\hline & $20(100)$ & $29(100)$ & $26(100)$ & $31(100)$ \\
\hline \multicolumn{5}{|l|}{ Radiological size alteration } \\
\hline shrinkage & $15(75)$ & $26(89)$ & $24(92.4)$ & $25(80.6)$ \\
\hline growth & $2(10)$ & $0(0)$ & $2(7.6)$ & $4(12.9)$ \\
\hline unchanged & $2(10)$ & $3(11)$ & $0(0)$ & $2(6.5)$ \\
\hline no data & $1(5)$ & $0(0)$ & $0(0)$ & $0(0)$ \\
\hline \multicolumn{5}{|l|}{ Regression pattern in the resection specimen } \\
\hline pCR & $0(0)$ & $6(20.7)$ & $12(46.2)$ & $12(38.7)$ \\
\hline uniform degree of regression & $11(55)$ & $3(10.3)$ & $2(7.6)$ & $4(12.9)$ \\
\hline lack of any regression & $3(15)$ & $1(3.4)$ & $1(3.8)$ & $3(9.6)$ \\
\hline Inhomogeneous & $6(30)$ & $19(65.6)$ & $11(42.3)$ & $12(38.7)$ \\
\hline minor inhomogeneity & $5(25)$ & $17(58.8)$ & $9(34.7)$ & $8(25.9)$ \\
\hline "scatter pattern" & $1(5)$ & $2(6.8)$ & $1(3.8)$ & $3(9.6)$ \\
\hline concentric shrinkage & $0(0)$ & $0(0)$ & $1(3.8)$ & $1(3.2)$ \\
\hline \multicolumn{5}{|l|}{ Regression pattern in the lymph node specimen } \\
\hline inhomogeneous & $7(35)$ & $10(34.5)$ & $4(15.4)$ & $4(12.9)$ \\
\hline not applicable & $4(20)$ & $7(24.2)$ & $9(34.6)$ & $13(41.9)$ \\
\hline \multicolumn{5}{|l|}{ Change in cellularity } \\
\hline decreased & $15(75)$ & $23(79.5)$ & $21(80.8)$ & $22(70.9)$ \\
\hline increased & $2(10)$ & $3(10.3)$ & $4(15.4)$ & $7(22.6)$ \\
\hline unchanged & $3(15)$ & $1(3.4)$ & $1(3.8)$ & $2(6.5)$ \\
\hline no data & $0(0)$ & $2(6.8)$ & $0(0)$ & $0(0)$ \\
\hline \multicolumn{5}{|l|}{ Change in grade } \\
\hline decreased & $4(20)$ & $3(10.3)$ & $3(11.5)$ & $0(0)$ \\
\hline increased & $2(10)$ & $5(17.3)$ & $0(0)$ & $3(9.6)$ \\
\hline unchanged & $14(70)$ & $12(41.4)$ & $11(42.3)$ & $15(48.3)$ \\
\hline no data & $0(0)$ & $9(31.0)$ & $12(46.2)$ & $13(41.9)$ \\
\hline \multicolumn{5}{|l|}{ Presence of "monster" cells } \\
\hline present & $5(25)$ & $6(20.6)$ & $3(11.5)$ & $5(16.1)$ \\
\hline absent & $15(75)$ & $23(79.4)$ & $23(88.4)$ & $26(83.9)$ \\
\hline
\end{tabular}

(HER-2: human epidermal growth factor receptor-2; TNBC: triple negative breast cancer, pCR: pathological complete regression) 
Table 3. Morphological characteristics of regression patters

\begin{tabular}{|l|c|c|c|c|c|c|c|c|c|}
\hline \multirow{2}{*}{$\begin{array}{c}\text { Patterns of } \\
\text { inhomogeneity }\end{array}$} & & \multicolumn{3}{|c|}{ complete regression pattern at magnification of/on } & \multicolumn{3}{c|}{ lack of any regression pattern at magnification of/on } \\
\cline { 2 - 11 } & $\mathbf{n}$ & $\mathbf{4 0 x}$ & $\mathbf{1 0 0 x}$ & whole slide & absent & $\mathbf{4 0 x}$ & $\mathbf{1 0 0 x}$ & whole slide & absent \\
\hline minor inhomogeneity & $\mathbf{3 9}$ & $19(48.7)$ & $14(35.8)$ & 0 & $6(15.5)$ & $15(35.5)$ & $9(23)$ & $3(7.8)$ & $12(30.7)$ \\
\hline scatter pattern & $\mathbf{7}$ & 0 & 0 & $7(100)$ & 0 & $2(28.5)$ & $3(43)$ & 0 & $2(28.5)$ \\
\hline concentric shrinkage & $\mathbf{2}$ & $2(100)$ & 0 & 0 & 0 & 0 & $1(50)$ & 0 & $1(50)$ \\
\hline
\end{tabular}

Note: When a pattern was present on the whole slide, it was also present in a medium power (10x) and low power field, too; but the numbers in the table reflect only the largest of the three areas assessed. 
Table 4. Relation between alterations of grade, therapy received and "monster" cells, respectively.

\begin{tabular}{|r|c|c|}
\hline & \multicolumn{2}{|c|}{ monster cells } \\
\hline Alteration of grade & present & absent \\
\hline increased & 5 & 5 \\
\hline decreased & 1 & 9 \\
\hline unchanged & 11 & 41 \\
\hline no data & 2 & 32 \\
\hline Therapy & & \\
\hline anthracycline +/- targeted therapy & 1 & 8 \\
\hline taxane +/- platinum derivatives & 4 & 23 \\
\hline anthracycline + taxane & 15 & 55 \\
\hline
\end{tabular}

